\title{
Publisher Correction: Central nervous system regulation of organismal energy and glucose homeostasis
}

Martin G. Myers Jr., Alison H. Affinati, Nicole Richardson (D) and Michael W. Schwartz $\mathbb{D}$

Correction to: Nature Metabolism https://doi.org/10.1038/s42255-021-00408-5, published online 21 June 2021.

In the version of this article originally published, the name of author Alison H. Affinati was incorrectly spelled as Alison H. Refined. The error has been corrected in the HTML and PDF versions of the article.

Published online: 29 June 2021

https://doi.org/10.1038/s42255-021-00431-6

(C) The Author(s), under exclusive licence to Springer Nature Limited 2021 